\title{
$*$ Pedometer determined Physical Activity viagal levels and Reliability of Pedometer data in Pakistani Adolescents
}

\author{
Shagufta Naseer
}

School of Public Health, Dow University of Health Sciences

\begin{abstract}
Background:Pedometer is the most convenient and economical objective tool which is progressively being used to assess physical activity in adolescents. The purpose of this study was to describe the overall and gender stratified physical activity levels and to determine minimal no. of reliable days for collecting pedometer data among Pakistani adolescents.
\end{abstract}

Methods:Descriptive cross-sectional study was conducted in four schools of Karachi during 2017. A total of 265 adolescents (age 13-16 years) wore unsealed Ymax Digi Walker SW-200 pedometer for a duration of 7 days including both weekends and weekdays. Data were analyzed using SPSS version 21. Independent $t$ test and ANOVA were used for gender based stratified physical activity levels whereas, Cronbach's alpha and Intra class correlation coefficient (ICC) were used to ascertain the reliability of pedometer data.

Results:The average recorded step counts per day were 10,010 (SD: \pm 4926). However, boys took 12,513 (SD: \pm 5365 ) steps / day than girls 7,809 (SD: \pm 3168 ) and higher steps were recorded from Thursday to Saturday. The reliability of pedometer monitoring increases with increase in number of days. The maximum pedometer reliability $\alpha=0.91$ was observed for 7 days.

Conclusion:This study concludes that adolescents are more physical active, with slightly higher reported activity among boys compared to girls. It also proposes that at least 7 days pedometer data should be collected for the reliable estimation of adolescent's physical activity. The resulting data provides key information regarding pedometer-determined physical activity which may be useful for formulating strategies and other interventions to increase level of adolescents physical activity

Keywords:Physical activity, adolescent, pedometer, Pakistan

\section{Introduction}

$\mathrm{T}$ he emerging public health issue among adolescence population is Physical inactivity (1). Physical Activity (PA) is the body movement which is produced by skeletal muscle on expenditure of energy $(2,3)$. It is evident that PA during childhood and adolescence plays an important role in maximizing growth and development (4). This phase is considered as the most critical phase of skeletal mineralization (5). In children of growing age, increase in daily PA results in increased bone mineral 
accrual and reduces the risk of fractures in later life (5). Those who are physically inactive may have elevated risk for chronic ailments such as cardiovascular diseases (CVD), particularly ischemic heart disease $(6,7)$, hypertension (8), hyperlipidemia (8), diabetes (9), atherosclerosis (8), osteoporosis (10) and obesity (11).

Moreover, obesity during childhood and adolescence may precede hyperinsulinemia and type II diabetes which can be prevented by increasing overall vigorous activities (8). In adolescents and older adults, PA is also beneficial in reducing anxiety and depression (12). PA is positively associated with self-esteem and academic performance in adolescents (13). On assessing the relationship between PA levels of parents and their young children, it was reported that children of active parents were found five times more active than children of inactive parents (14). During childhood, the social support from the friends aid in the early development of healthy habits of PA, which can also be observed throughout life (15). Additionally, lack of PA was one of the contributing factor of hypovitaminosis D among the young adults of Pakistan (16). In contemporary to this, it was noticed that online social networking might also hinder with the PA of students (17).

It is apparent that adolescents are more active than adults (18). Hence, it is difficult to measure their patterns of physical activity. Several studies had reported level of PA among adolescents by using selfreported questionnaires (19-23). The limitation observed in the use of self-reporting subjective assessment tools is recall bias for the frequency, duration and intensity of PA and misunderstanding of questions by the respondent (24-26).

Pedometer is an electronic device which measures vertical body movements as no. of steps taken. Due to its low cost and unobtrusiveness, it is considered as ideal tool for the assessment of PA in a large sample. Recently, the use of pedometers has been increased in assessment of daily physical activity (27-29). Pedometers are simple, small, cost effective, unobtrusive electronic devices which can be worn around waist $(1,18,30)$. It measures steps counts in account of vertical body movement and expressed as steps/day. The reason which make pedometer superior over other objective assessment tools (i.e. accelerometer, indirect calorimetry, doubly labeled water) is its cost effectiveness, easy monitoring via visible display of step counts and self - interpretability.
Since the use of pedometer has been rapidly increasing, Tudor - Locke et al had conducted various studies in which the referenced cut off criteria for healthy children, adolescents and adult were established (31-33). Based on the cut off recommendation used in former studies, 10,000 steps has been considered as a guide for the assessment of adolescent PA (34).

The aim of this study was to assess the overall and gender stratified physical activity levels among Pakistani adolescents (Age: 13 to 16 years, Grade 7 to 10) and to establish preliminary standards for comparison in determining appropriate physical activity levels of adolescents based on pedometer counts. Secondly, to determine the minimal number of reliable days for collecting pedometer data among Pakistani adolescents.

\section{Methodology}

The study was conducted in 4 schools of Karachi after taken the approval from Institutional Review Board of Dow University of Health Sciences (Ref: IRB680/DUHS/Approval/2016/170) and School administrations. In each school $(\mathrm{A}, \mathrm{B}, \mathrm{C}, \mathrm{D})$ the total number of students who met inclusion criteria of this study were 265, 318, 289 and 225 respectively. Informed consent was sent to the parents or guardians and after their permission, 66 participants were recruited randomly from each school. The sample consisted of 265 students ranging in age from 13 to 16 years.

Ymax Digi Walker SW-200 pedometer was used throughout this study because of its slim body, higher accuracy and reliability as reported in the previous studies $(18,35-39)$. Prior to the conduct of this study, the functionality and reliability of each pedometer was checked by performing a step count test. All of them pedometers were found to be within 5\% accuracy. The referenced cut-off criteria for pedometer step counts were used in this study (40). Adolescents who achieved $<10,000$ steps on all days of the week were considered physically inactive, those who achieved 10,000 steps on at least half of the days of the were moderately physical active and those who achieved 10,000 steps on all days of the week were physical active

Data were collected during the spring season between February to April 2017. Each week, participants from two to three classes were recruited in order to manage the process of data collection. The Ymax Digi Walker 
SW-200 pedometers were given for a period of 7 days including both weekdays and weekend. The pedometer data collection cycle lasted a week from Monday to Monday. The first period was selected for data collection in order to record the whole day activities. Unsealed pedometer was used during this study, as no significant difference in reactivity between sealed and unsealed pedometers were noted in previous studies $(34,36,41,42)$.

At the time of recruitment, the participants were instructed to wear it on the waist belt, parallel to the midline of thigh. They were asked to wear the pedometer from the time of awakening in the morning till the bedtime for the entire 7 days. Besides that, instructions for device safety were also given which include: resetting of device and detaching of device before going to bed or during water based activities (e.g swimming, showering). It was also emphasized to continue the normal routine activities during the study.

Training for recording each day's pedometer scores, and resetting of devices was given to sports teachers and the school doctor. The students were informed to report to their sports teacher or in doctor's room every morning from 8 to $8: 15$ a.m. for recording of pedometer step counts on their individual record sheet which was provided. Whereas, special instruction manual was sent to parents/ guardian to record the step counts for weekends. In order to reproduce the timings of weekday's steps recording, they were advised to record weekend steps as the foremost thing on Saturday and Sunday mornings.

The participants were also instructed not to wear pedometer for the rest of the day, if they forgot to wear it in the morning and record zero step on the record sheet. For the missing weekdays when the student forgot to wear the pedometer mean step counts were calculated. In case the student forgot to wear the pedometer on the weekend, it was given over for the next weekend in order to record the weekend step counts.

Statistical Analysis:

All the analysis was conducted in the Statistical Package for Social Sciences Software (SPSS) version 21. Descriptive statistics (Mean \pm SD, Range), frequencies and percentages for daily pedometer step counts were calculated for overall and gender stratified samples. Independent $\mathrm{t}$-test and ANOVA analysis were used to test for differences in average pedometer step counts between genders and within days respectively.
Ascertaining the reliability of pedometer in order to estimate the PA, Cronbach's alpha and Intra class correlation coefficient (ICC), were calculated from Two Way ANOVA model (Days $x$

Participants).

\section{Results}

In total, 265 students consented to take part in this study. Out of these, $141(53 \%)$ were girls with a mean age of 14 years, whereas 124 (47\%) were boys with mean age of 13 years. Among 265 participants, 227 $(85.7 \%)$ participants provided pedometer data for all 5 weekdays $(\mathrm{N}=26(9.8 \%)$ for 4 days, $12(4.5 \%)$ for 3 days). However, $100 \%$ response rate was recorded for the weekends. The descriptive statistics for pedometer step counts per day were shown in Table I.

The average recorded step counts per day were 10,010 (SD: \pm 4926$)$. However, boys took 12,513 (SD: \pm 5365 ) steps / day than girls 7,809 (SD: \pm 3168) and higher steps were recorded from Thursday to Saturday. Boys showed higher step counts on weekend (Saturday) in comparison to girls. Significant step count differential within days ( $\mathrm{p}$-value* <0.001) and in between both genders ( $\mathrm{p}$-value ${ }^{* *}<0.001$ ) was observed.

On the basis of overall pedometer step counts, 74 $(27.9 \%)$ adolescents were found inactive, $159(60 \%)$ adolescents were moderately active and $32(12 \%)$ adolescents were active. Among boys, 83 (66.9\%) were found more active whereas higher inactivity was recorded in girls i.e. $57(40 \%)$. The results revealed significant differences of pedometer step counts between males and females ( $p$-value $<0.001, \chi^{2}=28.95$ ) (Table II).

The reliability of pedometer over 7 consecutive days was estimated. Beginning with the initial 2 days (Mon - Tue) and subsequently added 1 day at a time. The increase in reliability was observed with increase in number of days. The minimally acceptable criterion value for reliability as defined by Nunnally Bernstein was $a \geq 0.70$ (36). This study reported utmost reliability of $\alpha=0.91$ for entire 7 days of monitoring. Analysis for the weekend and weekdays were also conducted separately. The reliability of pedometer step counts on weekdays $(\alpha=0.88)$ was higher than weekends $(\alpha=0.79)$. Furthermore, the pedometer reliability for all possible combinations of 2 to 7 days was assessed by performing Cronbach's alpha and Intra class Correlation Coefficient (ICC) analysis, the results of which were shown in Table III. The mean reliability coefficient $(\alpha)$ for 2 days was 0.73 , whereas, 
$0.80,0.84,0.86,0.89$ were observed for any 3, 4, 5 and 6 combinations, the mean reliability coefficient reached days respectively. With increasing number of days in 0.91 for 7 days.

Table I Estimated Daily Pedometer Step Counts $( \pm$ Standard Error) According to Gender and Time of week $(n=265)$

\begin{tabular}{|c|c|c|c|c|c|c|c|c|c|c|}
\hline Steps/day & \multicolumn{3}{|c|}{ Full sample $(n=265)$} & \multicolumn{3}{|c|}{ Male (n=124) } & \multicolumn{3}{|c|}{ Female $(n=141)$} & p-value** \\
\hline Monday & 9737 & 5855 & $990-35812$ & 12028 & 6936 & $990-35812$ & 7722 & 3692 & 1140 - 19211 & $<0.001$ \\
\hline Tuesday & 9759 & 5587 & $1107-30450$ & 11820 & 6176 & $2510-30450$ & 7947 & 4274 & 1107 - 21046 & $<0.001$ \\
\hline Wednesday & 9875 & 5712 & $1195-32000$ & 12377 & 6547 & $1256-32000$ & 7675 & 3667 & 1195 - 21991 & $<0.001$ \\
\hline Thursday & 10442 & 6516 & $1000-51189$ & 13450 & 7580 & $1916-51189$ & 7797 & 3811 & $1000-18579$ & $<0.001$ \\
\hline Saturday & 10150 & 6412 & 1018 - 38571 & 12769 & 7256 & $2108-38571$ & 7846 & 4454 & $1018-22080$ & $<0.001$ \\
\hline Sunday & 9887 & 6778 & 1092 - 40943 & 12738 & 7824 & $1800-40943$ & 7380 & 4396 & 1092 - 23296 & $<0.001$ \\
\hline p-value* & $<0.001$ & & & $<0.001$ & & & $<0.001$ & & & \\
\hline $\begin{array}{l}\text { Pedometer } \\
\text { Average } \\
\text { steps/day }\end{array}$ & 10010 & 4926 & $2427-27694$ & 12513 & 5365 & $3708-27694$ & 7809 & 3168 & $2427-18248$ & \\
\hline
\end{tabular}

p-value* calculated within groups-ANOVA

$\mathrm{p}$-value ${ }^{* *}$ calculated between groups-Independent t-test

Table II Overall and Gender Stratified Physical Activity Levels for sample of 265 Adolescents Based on Pedometer Step Counts

\begin{tabular}{|c|c|c|c|c|}
\hline & $\begin{array}{c}\begin{array}{c}\text { Full } \\
\text { sample }\end{array} \\
\mathrm{n}=265(\%)\end{array}$ & $\begin{array}{c}\text { Male } \\
\mathrm{n}=124 \\
(\%)\end{array}$ & $\begin{array}{c}\text { Female } \\
\mathrm{n}=141 \\
(\%)\end{array}$ & p-value \\
\hline \multicolumn{5}{|l|}{ Steps/day } \\
\hline \multirow{2}{*}{$\begin{array}{l}\text { Inactive } \\
\text { Moderate } \\
\text { active }\end{array}$} & 74 (27.9) & 17 (13.7) & $57(40.4)$ & \multirow{3}{*}{$\begin{array}{c}<0.001 \\
\left(X^{2}=28.95\right)\end{array}$} \\
\hline & $159(60.0)$ & $83(66.9)$ & $76(53.9)$ & \\
\hline Active & $32(12.1)$ & $24(19.4)$ & $8(5.7)$ & \\
\hline \multicolumn{5}{|c|}{$\begin{array}{l}\text { Note: For Pedometer Step Counts / day: Inactive }=\text { didn't } \\
\text { achieve 10,000 steps on any single day of all days, Moderate } \\
\text { Active }=\text { achieved 10,000 steps on at least half of the days, Active } \\
=\text { achieved 10,000 steps on all days } \\
\text { Table III Descriptive statistics for Reliability of Pedometer } \\
\text { Across Combinations of } 2 \text { - } 7 \text { Days of Monitoring for Sample } \\
265 \text { Adolescents }\end{array}$} \\
\hline \multirow[t]{2}{*}{$\begin{array}{c}\text { Combinatio } \\
\text { n of days }\end{array}$} & \multicolumn{2}{|c|}{$\begin{array}{c}\text { Reliability } \\
\text { Coefficient }(\mathbf{\alpha})\end{array}$} & \multicolumn{2}{|r|}{ ICC } \\
\hline & Mean & Range & Mean & Range \\
\hline 2 Days & 0.73 & $0.61-0.87$ & 0.58 & $0.48-0.78$ \\
\hline 3 Days & 0.80 & $0.77-0.87$ & 0.58 & $0.53-0.69$ \\
\hline 4 Days & 0.84 & $0.81-0.88$ & 0.58 & $0.48-0.78$ \\
\hline 5 Days & 0.86 & $0.86-0.88$ & 0.58 & $0.56-0.61$ \\
\hline 6 Days & 0.89 & 0.89 & 0.58 & $0.57-0.59$ \\
\hline 7 Days & 0.91 & 0.91 & 0.59 & 0.59 \\
\hline
\end{tabular}

ICC $=$ Intra class Correlation Coefficient

\section{Discussion}

The findings of current study show that majority of adolescents were moderately Physical Active. Boys on an average exhibited higher levels of PA than girls, whereas the level of PA was higher on weekdays as compared to weekends. Based on pedometer step counts, more than half $(60 \%)$ of the participants in our study, were moderately active. In our study, boys exhibited higher average step counts per day than girls, which is consistent when compared to the findings of other published studies from different countries $(27,30,33,34,43)$. The average reported steps for boys in our setting $(12513 \pm 5365)$ were found higher than New Zealand (10849 \pm 381) whereas, reported steps for New Zealand girls were higher (9625 \pm 289) than our findings (7809 \pm 3168). Adolescents of similar ages from US scored 2000 less steps / day in comparison to our study (36). Yet similar average step counts were observed among European countries (38). Keeping in view that such comparison of PA does not substantially reflect the overall difference between countries because neither data set is representative. While comparing the activities of weekdays and weekend, significantly low activity was noticed among both genders on weekend (Sunday). This increase in weekdays step counts may be because of the opportunities to participate in sports, games or physical education program during school timings. Cuberek (38), Clemes SA (35), Basette Jr (44) 
also had reported reduction of PA on Sunday. Evidence of significantly low PA on weekend was also reported among Indian adolescents (45). We feel that this decline in PA on Sundays is not random but reveals an inherent characteristic of fluctuations in real life behavior relating to PA. During weekdays, the routine of adolescents is challenging because of excessive activities at school, both mental and physical. Hence, weekend is considered as relaxation time and adolescents may not push themselves in activities. Secondly, due to law-and-order situation of our country, parents do not let their children to participate in outdoor activities such as cycling, playing cricket, football etc. Another striking factor contributing in reduction of PA is the advancements in the mode of entertainment and technology, due to which sedentary lifestyle is found more prevalent among adolescents of our setting $(46,47)$. The possible reason behind high number of step counts on weekdays is organized sports and vigorous PA during physical education (PE) classes and lunch time at school. Additionally, this research was administered during spring months of typical school year (February to April). During this season extra - curricular activities such as sports day, student week and annual function are also held in schools which can also be the possible reason of higher level of PA on weekdays.

The minimal acceptable criteria for pedometer reliability $(\alpha \geq 0.70)$ was defined by Nunnally and Bernstein (36). Our analysis indicated that 7 days of monitoring is required to attain reliability of $\alpha=0.91$ among adolescent age group. Previous studies reported the reliability of $a=0.80$ for 5 days measurement in 10 to 14 years of age $(36,48)$. Five days accrued similar reliability in our study. Robert $W$. et al reported reliability of $a=0.80$ for 3 days which was identical to the 3 days results of this study (37).

\section{Strengths and Limitation:}

To the best of our knowledge, the current study is the first conducted study in Pakistan which has assessed overall and gender stratified patterns of PA among adolescents by using objective assessment tool i.e. pedometer. The results of this study will be contributed in providing baseline data of PA among adolescents for future researches conducted in Pakistani settings.

This study has limitations. The data is from only four schools of Karachi, and the student's voluntary participation may have affected the generalizability of the results of this study. Similarly, adolescents who are not enrolled at any school were not included in this study, so the findings are only representing PA behavior of school going adolescents. For this study, data were collected during spring season so the amount of PA could be different in other seasons of the year simply due to weather variation. So the current study, due to its shorter duration, could not capture the changing PA behavior between different months. Similarly, the school used during this study had a large campus and playground which offered the opportunity to participate in moderate PA.

\section{Conclusion}

To the best of our knowledge, this is the first published study which not only reveal the moderate patterns of physical activity but has established an average cut off points of 10,000 steps per day for Pakistani adolescents. Based on the findings of this study, the PA levels in both genders were not same, also there were differences in day-to-day activities as well as statistically significant variation between weekend and weekday activities.

It is also found that the use of unsealed pedometer is an easy and inexpensive mode of objective assessment of PA among adolescents. This study also showed that minimal 7 days of recording pedometer data for adolescents provide highly reliable estimates of physical activity when worn across weekdays and weekends.

\section{Conflict of Interest:}

There was no conflict of interest. It was a self-funded study and a total of 30 pedometers were used

\section{References}

1. Clemes SA, Biddle S. The use of pedometers for monitoring physical activity in children and adolescents: measurement considerations. Sports, Exercise and Health Sciences. 2013;10(2):13.

2. Rangul V, Holmen TL, Kurtze N, Cuypers K, Midthjell K. Reliability and validity of two frequently used selfadministered physical activity questionnaires in adolescents. Biomedcentral Medical Research Methodology. 2008;8(1):47.

3. Martínez-Gómez D, Martínez-de-Haro V, Pozo T, Welk GJ, Villagra A, Calle ME, et al. Reliability and validity of the PAQ-A questionnaire to assess physical activity in 


\section{Pedometer determined Physical Activity levels and Reliability of Pedometer data in Pakistani Adolescents}

Spanish adolescents. Revista Española de Salud Pública. 2009;83(3):427-39.

4. Andersen RE, Crespo CJ, Bartlett SJ, Cheskin LJ, Pratt M. Relationship of physical activity and television watching with body weight and level of fatness among children: results from the Third National Health and Nutrition Examination Survey. Journal of American Medical Association. 1998;279(12):938-42.

5. Bailey D, McKay H, Mirwald R, Crocker P, Faulkner R. A six-year longitudinal study of the relationship of physical activity to bone mineral accrual in growing children: the University of Saskatchewan Bone Mineral Accrual Study. Journal of Bone and Mineral Research. 1999;14(10):1672-9.

6. Mora S, Cook N, Buring JE, Ridker PM, Lee I-M. Physical activity and reduced risk of cardiovascular events potential mediating mechanisms. Medicine and Science in Sports and Exercise. 2007;116(19):2110-8.

7. Kohl 3rd H. Physical activity and cardiovascular disease: evidence for a dose response. Medicine and Science in Sports and Exercise. 2001;33(sup 6):472-94.

8. Steinberger J, Daniels SR. Obesity, Insulin Resistance, Diabetes, and Cardiovascular Risk in Children An American Heart Association Scientific Statement From the Atherosclerosis, Hypertension, and Obesity in the Young Committee (Council on Cardiovascular Disease in the Young) and the Diabetes Committee (Council on Nutrition, Physical Activity, and Metabolism). American Heart Association Journal. 2003;107(10):144853.

9. Helmrich SP, Ragland DR, Leung RW, Paffenbarger Jr RS. Physical activity and reduced occurrence of noninsulin-dependent diabetes mellitus. New England Journal of Medicine. 1991;325(3):147-52.

10. Prince SA, Adamo KB, Hamel ME, Hardt J, Gorber SC, Tremblay M. A comparison of direct versus self-report measures for assessing physical activity in adults: a systematic review. International Journal of Behavioral Nutrition and Physical Activity. 2008;5(1):56.

11. Bar-Or O, Baranowski T. Physical activity, adiposity, and obesity among adolescents. Pediatric Exercise Science. 1994;6(4):348-59.

12. Paluska SA, Schwenk TL. Physical activity and mental health. Sports Medicine. 2000;29(3):167-80.

13. Nelson MC, Gordon-Larsen P. Physical activity and sedentary behavior patterns are associated with selected adolescent health risk behaviors. Pediatrics. 2006;117(4):1281-90.

14. Moore LL, Lombardi DA, White MJ, Campbell JL, Oliveria SA, Ellison RC. Influence of parents' physical activity levels on activity levels of young children. The Journal of Pediatrics. 1991;118(2):215-9.

15. Maturo CC, Cunningham SA. Influence of friends on children's physical activity: a review. American Journal of Public Health. 2013;103(7):23-38.
16. Roomi MA, Farooq A, Ullah E, Lone KP Hypovitaminosis D and its association with lifestyle factors. Pakistan Journal of Medical Sciences. 2015;31(5):1236.

17. Farooqi H, Patel H, Aslam HM, Ansari IQ, Khan M, Iqbal $\mathrm{N}$, et al. Effect of Facebook on the life of Medical University students. International Archives of Medicine. 2013;6(1):1.

18. Wilde BE, Corbin CB, Le Masurier GC. Free-living pedometer step counts of high school students. Pediatric Exercise Science. 2004;16(1):44-53.

19. Thompson AM, Baxter-Jones AD, Mirwald RL, Bailey DA. Comparison of physical activity in male and female children: does maturation matter? Medicine and science in sports and exercise. 2003;35(10):1684-90.

20. Janz KF, Lutuchy EM, Wenthe P, Levy SM. Measuring activity in children and adolescents using self-report: PAQ-C and PAQ-A. Medicine and Science in Sports and Exercise. 2008;40(4):767-72.

21. Yasmin K, Taghdisi MH, Nourijelyani K. Psychological Well-Being (PWB) of School Adolescents Aged 12-18 yr, its Correlation with General Levels of Physical Activity (PA) and Socio-Demographic Factors In Gilgit, Pakistan. Iranian Journal of Public Health. 2015;44(6):804.

22. Adeniyi AF, Okafor NC, Adeniyi CY. Depression and physical activity in a sample of nigerian adolescents: levels, relationships and predictors. Child \& Adolescent Psychiatry \& Mental Health. 2011;5(1):16.

23. CRIMI K, HENSLEY LD, FINN KJ. Psychosocial correlates of physical activity in children and adolescents in a rural community setting. International Journal of Exercise Science. 2009;2(4).

24. Campbell CM. Methods of physical activity assessment in older adults. 2012.

25. Rowlands AV, Eston RG, Ingledew DK. Measurement of physical activity in children with particular reference to the use of heart rate and pedometry. Sports medicine. 1997;24(4):258-72.

26. Welk GJ, Corbin CB, Dale D. Measurement issues in the assessment of physical activity in children. Research Quarterly for Exercise and Sport. 2000;71(sup2):59-73.

27. Hands B, H.Parker. Pedometer determined physical activity, BMI, waist girth in 7 to 16 year old children and adolescents. Journal of Physical Activity \& Health. 2008;5(1):153-65.

28. Pangrazi RP, Corbin CB, Rutherford WJ, Vincent SD, Raustorp A, Tomson L, et al. BMI-referenced standards for recommended pedometer-determined steps/day in children. 2015.

29. Rowlands AV, Eston RG. Comparison of accelerometer and pedometer measures of physical activity in boys and girls, ages 8-10 years. Research quarterly for exercise and sport. 2005;76(3):251-7.

30. Hohepa M, Schofield G, Kolt GS, Scragg R, Garrett N. Pedometer-determined physical activity levels of adolescents: differences by age, sex, time of week, and 
transportation mode to school. Journal of Physical Activity \& Health. 2008;5(1):140 - 52.

31. Craig CL, Tudor-Locke C, Cragg S, Cameron C. Process and treatment of pedometer data collection for youth: the Canadian Physical Activity Levels among Youth study. Medicine and Science in Sports and Exercise. 2010;42(3):430-5.

32. Tudor-Locke C, Craig CL, Rowe DA, Spence JC, Tanaka S, Blair SN, et al. How many steps/day are enough? for children and adolescents. International Journal of Behavioral Nutrition and Physical Activity 2011;8(78):1 14.

33. Tudor-Locke C, Pangrazi RP, Corbin CB, Rutherford WJ, Vincent SD, Raustorp A, et al. BMI-referenced standards for recommended pedometer-determined steps/day in children. Preventive Medicine. 2004;38(6):857-64.

34. Abbott RA, Macdonald D, Nambiar S, Davies PS. The association between walking to school, daily step counts and meeting step targets in 5-to 17-year-old Australian children. Pediatric Exercise Science. 2009;21(4):520.

35. Clemes SA, Griffiths PL. How many days of pedometer monitoring predict monthly ambulatory activity in adults? Medicine and Science in Sports and Exercise. 2008;40(9):1589-95.

36. Rowe DA, Mahar MT, Raedeke TD, Lore J. Measuring physical activity in children with pedometers: Reliability, reactivity, and replacement of missing data. Pediatric Exercise Science. 2004;16(4):343-54.

37. Motl RW, Zhu W, Park Y, McAuley E, Scott JA, Snook EM. Reliability of scores from physical activity monitors in adults with multiple sclerosis. Adapted Physical Activity Quarterly. 2007;24(3):245-53.

38. Cuberek R, El Ansari W, Frömel K, Skalik K, Sigmund E. A comparison of two motion sensors for the assessment of free-living physical activity of adolescents. International Journal of Environmental Research and Public Health. 2010;7(4):1558-76.

39. Schneider PL, Crouter SE, Lukajic O, Bassett DR. Accuracy and reliability of 10 pedometers for measuring steps over a 400-m walk. Medicine and Science in Sports and Exercise. 2003;35(10):1779-84.

40. Hohepa M, Schofield G, Kolt GS, Scragg R, Garrett N. Pedometer-determined physical activity levels of adolescents: differences by age, sex, time of week, and transportation mode to school. Journal of physical activity and health. 2008;5(s1):S140-S52.

41. Ozdoba RS, Corbin CB, Lemasurier GC. Does reactivity exist in children when measuring activity levels with unsealed pedometers? Pediatric Exercise Science. 2004:158-66.

42. Rowlands A, Eston RG. The measurement and interpretation of children's physical activity. Journal of Sports Science and Medicine. 2007;6(1):7.

43. Dollman J, Olds TS, Esterman A, Kupke T. Pedometer step guidelines in relation to weight status among 5-to 16-year-old Australians. Pediatric Exercise Science. 2010;22(2):288-300.

44. Bassett Jr DR, Cureton AL, Ainsworth BE. Measurement of daily walking distance-questionnaire versus pedometer. Medicine and Science in Sports and Exercise. 2000;32(5):1018-23.

45. Contractor A, Bhanushali A, Changrani J, Angadia S, Das BR. Pedometer assessed physical activity in urban pubertal children: first report from India. Journal of Physical Activity \& Health. 2014;11(8):1475-81.

46. Qidwai W, Ishaque S, Shah S, Rahim M. Adolescent lifestyle and behaviour: A survey from a developing country. PLOS One. 2010;5(9):12914.

47. Rosen LD, Lim A, Felt J, Carrier LM, Cheever NA, LaraRuiz J, et al. Media and technology use predicts ill-being among children, preteens and teenagers independent of the negative health impacts of exercise and eating habits. Computers in Human Behavior. 2014;35(1):36475.

48. Strycker LA, Duncan SC, Chaumeton NR, Duncan TE, Toobert DJ. Reliability of pedometer data in samples of youth and older women. International Journal of Behavioral Nutrition and Physical Activity. 2007;4(1-8). 